\title{
Molecular Biology of Lung Cancer
}

\author{
Diagnosis and Management of Lung Cancer, \\ 3rd ed: American College of Chest Physicians \\ Evidence-Based Clinical Practice Guidelines
}

\author{
Serge Patrick Nana-Sinkam, MD, FCCP; and Charles A. Powell, MD, FCCP
}

\begin{abstract}
Based on recent bench and clinical research, the treatment of lung cancer has been refined, with treatments allocated according to histology and specific molecular features. For example, targeting mutations such as epidermal growth factor receptor (EGFR) with tyrosine kinase inhibitors has been particularly successful as a treatment modality, demonstrating response rates in selected patients with adenocarcinoma tumors harboring EGFR mutations that are significantly higher than those for conventional chemotherapy. However, the development of new targeted therapies is, in part, highly dependent on an improved understanding of the molecular underpinnings of tumor initiation and progression, knowledge of the role of molecular aberrations in disease progression, and the development of highly reproducible platforms for high-throughput biomarker discovery and testing. In this article, we review clinically relevant research directed toward understanding the biology of lung cancer. The clinical purposes of this research are (1) to identify susceptibility variants and field molecular alterations that will promote the early detection of tumors and (2) to identify tumor molecular alterations that serve as therapeutic targets, prognostic biomarkers, or predictors of tumor response. We focus on research developments in the understanding of lung cancer somatic DNA mutations, chromosomal aberrations, epigenetics, and the tumor microenvironment, and how they can advance diagnostics and therapeutics.
\end{abstract}

CHEST 2013; 143(5)(Suppl):e30S-e39S

Abbreviations: ALK $=$ anaplastic lymphoma kinase; EGFR $=$ epidermal growth factor receptor; EML4 = echinoderm microtubule-associated protein like-4; FDA = US Food and Drug Administration; FGFR = fibroblast growth factor receptor; FISH $=$ fluorescent in situ hybridization; miRNA = microRNA; NSCLC $=$ non-small cell lung cancer; PCR $=$ polymerase chain reaction; $\mathrm{SCC}=$ squamous cell carcinoma; $\mathrm{TKI}=$ tyrosine kinase inhibitor

$\mathbf{L}$ ung cancer is the leading cause of cancer death in

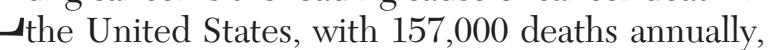
and in the world, with 1,375,000 deaths annually. ${ }^{2}$ The overall 5 -year survival for lung cancer remains at $16 \%$, which is significantly lower than the mortality rate for other common cancers, including colon, breast, and prostate cancer. The discrepancy in the mortality rate of lung cancer compared with other cancers has several explanations. First, lung cancers are typically detected at an advanced stage. The anticipated implementation of population-based screening for lung cancer is expected to decrease mortality. Second, compared with the other common cancers that share adenocarcinoma as the histology, lung cancer is heterogenous histologically and biologically. Until recently, lung cancer was treated as a homogenous disease with all non- small cell lung cancers (NSCLCs) treated identically, solely on the basis of clinical stage. Based on bench and clinical research, the treatment of lung cancer has been refined, with treatments allocated according to histology and specific molecular features. For example, targeting mutations such as epidermal growth factor receptor (EGFR) with tyrosine kinase inhibitors (TKIs) has been particularly successful as a treatment modality, demonstrating response rates in patients with EGFR-mutated adenocarcinoma that are significantly higher than those for conventional chemotherapy. However, the development of new targeted therapies is, in part, highly dependent on an improved understanding of the molecular underpinnings of tumor initiation and progression, knowledge of the role of molecular aberrations in disease progression, 
and the development of highly reproducible platforms for high-throughput biomarker discovery and testing.

In this article, we review the clinically relevant research directed toward the molecular biology of lung cancer. The clinical purposes of this research are (1) to identify susceptibility variants and field molecular alterations that will promote the early detection of tumors and (2) to identify tumor molecular alterations that serve as therapeutic targets, prognostic biomarkers, or predictors of tumor response. The literature review was restricted to English-language papers from 2007 to 2012 that addressed the following six topics: somatic mutations in NSCLC; lung developmental and differentiation pathways in adenocarcinoma and squamous cell carcinoma (SCC); copy number alterations and gene rearrangements in NSCLC; epigenetic changes in promoter hypermethylation and microRNA (miRNA) expression in NSCLC; lung tumor microenvironment; and EGFR, $\mathrm{K}$-ras, and echinoderm microtubule-associated protein like-4 (EML4)/anaplastic lymphoma kinase (ALK) alterations treated with TKIs of ALK inhibitors.

\subsection{LUNG CARCINOGENESIS}

The processes of tumor initiation and progression involve a multitude of orchestrated steps that encompass DNA damage and mutations induced by cigarette smoke carcinogens, to field carcinogenesis and preneoplasia in the airway epithelium, to the develop-

Manuscript received September 24, 2012; revision accepted November 30, 2012

Affiliations: From the Division of Pulmonary, Allergy, Critical Care and Sleep Medicine (Dr Nana-Sinkam), Medical Oncology, Ohio State University, Columbus, OH; and the Division of Pulmonary, Critical Care and Sleep Medicine (Dr Powell), Mount Sinai School of Medicine, New York, NY.

Funding/Sponsors: The overall process for the development of these guidelines, including matters pertaining to funding and conflicts of interest, are described in the methodology article. ${ }^{1}$ The development of this guideline was supported primarily by the American College of Chest Physicians. The lung cancer guidelines conference was supported in part by a grant from the Lung Cancer Research Foundation. The publication and dissemination of the guidelines was supported in part by a 2009 independent educational grant from Boehringer Ingelheim Pharmaceuticals, Inc. COI Grids reflecting the conflicts of interest that were current as of the date of the conference and voting are posted in the online supplementary materials.

Disclaimer: American College of Chest Physician guidelines are intended for general information only, are not medical advice, and do not replace professional medical care and physician advice, which always should be sought for any medical condition. The complete disclaimer for this guideline can be accessed at http:// dx.doi.org/10.1378/chest.1435S1.

Correspondence to: Charles A. Powell, MD, Division of Pulmonary, Critical Care and Sleep Medicine, Mount Sinai School of Medicine, One Gustave Levy Place, Box 1232, New York, NY 10029; e-mail: Charles.powell@mssm.edu

(C) 2013 American College of Chest Physicians. Reproduction of this article is prohibited without written permission from the American College of Chest Physicians. See online for more details. DOI: $10.1378 /$ chest.12-2346 ment of the tumor. Each of these critical steps remains the focus of intense clinical and laboratory investigation. Although tobacco consumption remains the primary risk factor for the development of lung cancer, only $10 \%$ of smokers develop lung cancer. Thus, interindividual differences in susceptibility as modulated by genetic and epigenetic factors play an important role in lung carcinogenesis. In reviews, Hanahan and Weinberg ${ }^{3,4}$ outlined the crucial molecular alterations that are important for cancer development. In the following sections, we outline several of these cancer hallmarks as they apply specifically to lung cancer.

\subsection{Somatic DNA Mutations}

Multiple somatic mutations contribute to malignant transformation in lung cancer. Mutations within tumor suppressors, oncogenes, and DNA repair-related genes may function in concert to confer a biologic advantage to tumors. Mutations at the chromosomal level (3p, 9p21, 12p, 17p13, 13q) in the form of loss of heterozygosity, translocations, deletions, and point mutations have all been well described in lung cancer. ${ }^{5-7}$ These mutations, in turn, may be used as diagnostic and prognostic biomarkers. The development of rapid and sensitive sequencing technologies has advanced the characterization of the multitude of somatic mutations inherent in many tumors.

Early studies using sequencing technologies were focused on individual target genes such as p53 and p16.8,9 Traditionally, Sanger sequencing has served as the primary modality for exon-based sequencing, but it has limitations that include decreased sensitivity for the detection of low-frequency mutations. The majority of sequencing-based investigations have been designed to target specific tumor suppressors and oncogenes. The Tumor Sequencing Project, conducted in 188 cases of lung cancer, identified 26 genes that harbored mutations significantly above the baseline rate in uninvolved adjacent tissue,${ }^{10}$ including several commonly identified mutations in EGFR, p53, and $\mathrm{K}-\mathrm{ras}$, among others. More advanced techniques that survey the genome now allow for the simultaneous detection of multiple mutations. A recent demonstration of a comprehensive approach to whole-genome sequencing in a patient with adenocarcinoma demonstrated not only previously identified mutations within K-ras, TP53, and CDK4, but numerous less welldescribed mutations within genes such as NEK9 and MUC16. ${ }^{11}$ In addition, investigators were able to identify mutations within nonprotein coding regions. This study and others confirm the concept that single tumors may harbor several genomic aberrations ranging from those at the chromosomal level down to single nucleotide variations that all must be taken into consideration with prognosis and treatment response in the 
correlation of mutations. Su et al ${ }^{12}$ described two assays termed $\mathrm{SNaPshot}$ and polymerase chain reaction (PCR)-based sizing assays that may also be used to detect select somatic mutations in genes commonly implicated in cancer. High-resolution melting represents another PCR-based platform for initial mutation screening that holds some promise. ${ }^{13,14}$ In the future, it is likely that exon-specific or whole-genome-based sequencing will supplant existing technologies for screening tumor genome alterations.

\subsection{Lung Developmental and Differentiation Pathways}

Current paradigms suggest that lung carcinomas arise from pluripotent stem and progenitor cells capable of differentiation into one or several histologic cell types. These paradigms suggest that lung tumor cell ontology is determined by the consequences of gene transcriptional activation and/or repression events that recapitulate embryonic lung development. ${ }^{15-17}$ The hypothesis that lung cancer arises from the aberrant expression of genes involved in lung development is supported by gene expression studies demonstrating similarities between signatures obtained from human lung tumors and signatures characteristic of normal lung development. ${ }^{18,19}$ Genes associated with early lung development are more often expressed by small cell lung carcinoma and by other aggressive tumors with poor prognosis. ${ }^{20,21}$ Taken together, these observations suggest that poor differentiation is linked to the molecular parameters of early development representing lung stem and progenitor cell programs, and that the gene signatures of these phenotypes are important for lung cancer progression and clinical outcome.

The importance of identifying the NSCLC histologic subtype has increased recently because of the demonstrated success of histology-specific chemotherapeutic regimens. Until recently, all patients with NSCLC were treated without regard for histologic subtype. The first data suggesting the importance of histologic dependence were shown in the phase I-II trials of the vascular endothelial growth factor antibody bevacizumab. ${ }^{22}$ These results indicated that the drug was effective, but that toxicity was increased in patients with squamous histology. Subsequent trials (eg, Eastern Cooperative Oncology Group 4599) were restricted to patients with nonsquamous histology, ${ }^{23}$ and current US Food and Drug Administration (FDA) approval is applicable to these patients only.

More recent clinical studies have shown a major treatment-by-histology interaction in the responsiveness of advanced stage IV NSCLC to pemetrexed. Scagliotti and colleagues ${ }^{24}$ performed an interaction analysis of the three pivotal phase 3 studies leading to the approval of pemetrexed in the first-line, secondline, and maintenance settings. The results demonstrated clear-cut and very significant treatment-by-histology interactions with regard to both progression-free and overall survival, thus confirming the superior efficacy of pemetrexed in patients with nonsquamous NSCLC. ${ }^{25}$ In addition, mutations of EGFR and K-ras and translocations of EML4/ALK are largely confined to adenocarcinoma. ${ }^{26}$ These findings have prompted a major shift toward targeted therapy in lung cancer management, as detailed by Socinski et $\mathrm{al}^{27}$ in the article, "Treatment of Stage IV Non-small Cell Lung Cancer," in the American College of Chest Physicians Lung Cancer Guidelines, thus mandating that diagnostic specimens be acquired and processed in a fashion that permits the histologic subtyping of NSCLC. ${ }^{28}$ In studies using immunostains to subtype NSCLC in cytologic specimens, Loo et a $\mathrm{a}^{29}$ and Nicholson et a ${ }^{30}$ showed that thyroid transcription factor- 1 and mucin vs p63 stains are the best stains for detecting adenocarcinoma vs SCC, respectively. However, none of the antibodies used in immunohistochemistry is $100 \%$ specific and sensitive for this differential diagnosis. Further details on clinical immunophenotyping of lung cancer are found in the article by Schwartz and Rezaei, ${ }^{31}$ "Diagnostic Surgical Pathology in Lung Cancer," in the American College of Chest Physicians Lung Cancer Guidelines.

Identification of putative progenitor cells and stem cells of lung cancer is an active area of investigation. The objective is to target these cells to prevent cancer development and to treat established lung cancer. To date, no cell that strictly exemplifies the hallmarks of a stem cell has been confirmed as a lung cancer stem cell. Putative stem and progenitor cells include basal cells expressing p63 and cytokeratins 5 and 14, ${ }^{32}$ epithelial cells expressing the five-transmembrane glycoprotein CD133, ${ }^{33}$ isolated cancer cells with high activity of aldehyde dehydrogenase $1,{ }^{34}$ and bronchioloalveolar stem cells identified at the bronchioloalveolar duct junction in a murine model of lung cancer. ${ }^{35}$

\subsection{DNA Copy Number Alterations and Gene Rearrangements}

Chromosomal abnormalities including amplifications, deletions, and rearrangements have been investigated extensively in lung cancer. One commonly used assay, fluorescent in situ hybridization (FISH), relies on fluorescent labeled DNA segments to detect regions with chromosomal aberrations. Early studies demonstrated that FISH could identify chromosomal aneuploidy in established lung cancer samples ranging from primary tumors, to effusions, to bronchial washings. ${ }^{36}$ Sokolova et al ${ }^{37}$ showed that FISH carried a sensitivity of $84 \%$ and a specificity of $82 \%$ in the 
detection of lung cancer in bronchial washings. The results from several studies suggest that FISH could complement the diagnostic accuracy of cytology. For example, Nakamura et al ${ }^{38}$ compared FISH with conventional cytology and determined that FISH had a specificity of $100 \%$ and a sensitivity of $87 \%$. Halling et al ${ }^{39}$ detected a sensitivity of FISH of $71 \%$ in bronchial brushing specimens and $49 \%$ in bronchial washing specimens. Select FISH probes have been used as a diagnostic assay for the detection of lung cancer. ${ }^{39-41}$ For example, in a cohort of patients with lung cancer and a control group with nonneoplastic disease, FISH for MYC (8q24), EGFR (7p12), and chromosomes 5 and 6 in bronchial brushings showed increased sensitivity compared with conventional cytology. ${ }^{42}$ Varella-Garcia et al ${ }^{43}$ recently showed that chromosomal aneusomy in sputum as detected by FISH may be useful in the early detection of lung cancer.

An emerging application for FISH technology has been to determine EGFR status and, thus, TKI sensitivity. Mutational analysis for EGFR is increasingly becoming standard in the assessment of adenocarcinomas, given the significant response rates to EGFR/ TKI inhibitors among patients harboring mutations. ${ }^{44,45}$ The role of the EGFR copy number in determining therapy or response remains unclear. Some studies suggest that the EGFR copy number correlates with mutational status and, to a lesser extent, with drug responsiveness. ${ }^{46}$ Another study confirmed that mutational status is the most valuable predictor of responsiveness, independent of copy number or protein expression. ${ }^{47}$ Several phase 2 and 3 trials have been conducted to answer this question, but the results have been inconsistent. ${ }^{48,49}$ Two meta-analyses confirmed that EGFR mutational analysis, not FISH, is the assay of choice to predict response to TKI therapy. ${ }^{50,51}$

The EML4/ALK protein represents a fusion between ALK and EML4 that is present in approximately $4 \%$ of NSCLC. ${ }^{52,53}$ The rearrangement is associated with response to the targeted ALK inhibitor crizotinib. A comparison of different methodologies for dysregulated ALK detection concluded that ALK break-apart FISH could accurately detect rearrangements. ${ }^{54}$ Thus, the break-apart assay is now FDA approved to determine treatment with crizotinib. However, studies are ongoing to determine if a complementary set of assays, including immunohistochemistry, FISH, and reverse transcription-PCR, may be helpful in clinical decision making.

SOX2, located at chromosome $3 q 26.33$, is a transcription factor gene involved in foregut development and pluripotency that has been shown to be amplified in SCCs, including lung. ${ }^{55,56}$ In fact, SOX2 carries a specificity of $95 \%$ in distinguishing SCC from adenocarcinoma. ${ }^{57}$ Several studies have shown that SOX2 has oncogenic properties and that direct targeting can suppress both metastases and growth. Interestingly, elevated SOX2 may correlate with a favorable prognosis in SCC ${ }^{58}$ but an unfavorable prognosis in stage 1 adenocarcinoma. ${ }^{59}$

Fibroblast growth factor receptor (FGFR) 1 is selectively amplified in SCC (22\%). Reports from in vivo and in vitro studies indicate that FGFR1 amplification signifies sensitivity to treatment of SCC with FGFR inhibitors. ${ }^{60}$ Additional studies suggest that metastatic SCC may be particularly susceptible to antiFGFR agents. ${ }^{61}$ TKIs including ponatinib (AP24534), which have potent anti-FGFR properties, are currently being investigated in lung cancer in phase 1 trials. ${ }^{62}$

\subsection{EPIGENETICS}

\subsection{Methylation}

Over the past several years, investigators have determined that epigenetic changes within the human genome at the level of chromatin remodeling, histone modifications, and DNA methylation can alter the expression patterns of critical tumor suppressors and oncogenes to influence malignant transformation. Aberrant hyper- and hypomethylation of $\mathrm{CpG}$ islands represent the most common finding, ranging from $15 \%$ to $80 \%$ of lung cancers. ${ }^{63}$ Several genes that have been identified, including CDKN2A, FHIT, APC, p16, and RASSF1A, appear to be commonly methylated. ${ }^{64-67}$

Methylated genes may be detected using several techniques. The majority of early studies used technologies such as methylation-specific PCR and restriction landmark genomic scanning, which are targeted to specific genomic regions and candidates. These techniques have proven successful in identifying patterns of methylation that distinguish tumor from normal tissues and also in identifying clinical subgroups. ${ }^{68}$ High-throughput profiling allows for global epigenetic analysis for candidate genes within promoter $\mathrm{CpG}$ islands; $3^{\prime}$ untranslated regions; and noncoding regions of the genome, including miRNA, long noncoding RNAs, and ultraconserved regions. ${ }^{69}$

Both global and gene-specific epigenetic changes are being tested as noninvasive biomarkers for early detection and prognosis of lung cancer. ${ }^{70,71}$ Systematic examination of the "methylome" can be used to further subclassify molecular and clinically distinct subgroups of lung cancer and to potentially guide therapeutic decisions. Brock et al ${ }^{72}$ examined the prognostic value of methylation patterns for seven genes (p16, MGMT, DAPK, RASSF1A, CDH13, ASC, and $A P C)$ in the setting of resected stage 1 NSCLC. The authors demonstrated that pairs of gene combinations of $p 16, C D H 13, A P C$, and RASSF1A served as risk factors for recurrence. Methylation analysis for specific genes is now being applied to biomarker 
discovery efforts using noninvasive specimens. Belinsky et $\mathrm{al}^{73}$ demonstrated in sputum that the analysis of methylation patterns in a panel of predetermined genes had predictive value for the eventual development of lung cancer among high-risk smokers. An independent study concluded that methylation patterns within sputum correlated much better with primary tumor than did methylation within serum. ${ }^{74}$

Epigenetics analysis is being integrated into clinical trials. De Fraipont et al ${ }^{75}$ examined tumor samples for methylation of RASSF $1 a$ and DAPK1 within the French Intergroup (IFCT-0002) phase 3 trial of neoadjuvant treatment of stage I to II NSCLC and determined that methylation of both genes showed prognostic efficacy.

\section{2 microRNA}

During the past 2 decades, investigators have determined that large noncoding portions of the human genome may harbor functional capacity. These regions of noncoding RNA are now known to have gene regulatory function. miRNAs (or miRs) represent perhaps the best studied of this group of noncoding RNAs. ${ }^{76,77}$ Currently, there are $>1,200$ human miRNAs. Based on in silico analysis, miRNAs may regulate up to twothirds of the human genome. ${ }^{78}$ miRNAs have been implicated in all the fundamental hallmarks of cancer initiation and progression. Profiling studies have demonstrated global differences in miRNA expression between lung tumor and noninvolved adjacent lung tissues. ${ }^{79}$ These initial observations have led to research focused on functional in vitro and in vivo validation of single-miRNA single-target relationships and on linking patterns of miRNA expression to clinical parameters such as prognosis and therapeutic response.

Several studies have examined miRNAs as prognostic biomarkers in lung cancer. The earliest studies in stage 1 adenocarcinomas demonstrated that increased miR-155 and decreased Let-7a2 correlated with poor survival. ${ }^{79}$ Landi et al ${ }^{80}$ identified a 5 -miRNA signature that correlated with survival. Saito et al ${ }^{81}$ determined that miR-21 consistently correlated with poor outcomes among early lung stage cancers from three independent cohorts. Another study suggested that patterns of plasma miRNA may be used for risk stratification in lung cancer screening programs. ${ }^{82}$ Other studies have been unsuccessful in correlating miRNA to outcome. A study among patients undergoing surgical resection and adjuvant chemotherapy found no association between select miRNAs and survival or response to therapy. ${ }^{83} \mathrm{~A}$ few select miRNAs have emerged as having the capacity to distinguish histologic subtypes. Several studies have determined that miR-205, which is overexpressed in SCC compared with adenocarcinoma, can be used to distinguish the histologies. ${ }^{84-86}$ The role of miRNA in the clinical setting remains unclear, awaiting large, prospective profiling studies that demonstrate reproducibility.

\subsection{Tumor Microenvironment}

The past few decades have seen a new appreciation for the role of the tumor stroma in cancer initiation and progression. ${ }^{87}$ Signaling between the stroma and epithelium, via direct contact and secreted mediators, is essential for tumor initiation, growth, differentiation, progression, and metastasis..$^{88}$ The tumor stroma is a complex system composed of fibroblasts (cancerassociated fibroblasts), macrophages (tumor-associated macrophages), other immune cells, vasculature, and extracellular matrix. ${ }^{89}$ Cancer cells modulate the stromal microenvironment via secretion of a variety of growth factors, including transforming growth factor- $\beta,{ }^{90}$ platelet-derived growth factor, vascular endothelial growth factor, and basic fibroblast growth factor. In turn, the stroma can produce antiangiogenic factors and recruit an antitumor immune response. Alternatively, the stromal response can facilitate tumor progression via the release of growth factors that feed back to tumor cells, participate in new vessel growth, and promote tumor growth and invasion. ${ }^{87}$ The stroma can have powerful tumor-promoting effects. For example, culturing cancer-associated fibroblasts with initiated prostatic epithelial cells enhances tumor growth and invasion, ${ }^{91}$ and in a murine model, loss of T $\beta R I I$ in fibroblasts can promote tumor initiation in the adjacent epithelium..$^{92}$ In addition to its roles in lung tumor initiation and progression, the stroma, in cooperation with tumor cells, can establish a niche within the lung that is conducive to the establishment and growth of metastatic foci from other primary tumors. ${ }^{93,94}$

Several researchers have directed research toward understanding the prognostic significance of immune cell composition within and surrounding the lung tumor. Various immune cell compartments have been examined, including macrophages (M1 vs M2), T-helper (CD4 and CD8) cells, cytotoxic T cells, T-regulatory cells, B cells, natural killer cells, neutrophils, and myeloid-derived suppressor cells. ${ }^{95}$ To date, there is no validated immune cell biomarker of prognosis. The fields of cancer immunology and immunotherapy are evolving; thus, it is possible that further research will provide clinically important biomarkers of prognosis and predictors of response to immunotherapy.

\subsection{ONCOGENE AdDICTION: EGFR, K-RAS, EML4/ALK ALTERATIONS}

The oncogene addiction hypothesis states that precise targeting of discrete fundamental genetic alterations in tumors will kill tumor cells and result in 
clinical response. ${ }^{96}$ The successful application of this principle has been demonstrated in lung adenocarcinoma using agents targeted toward EGFR and ALK. ${ }^{97}$

EGFR is a $170-\mathrm{kDa}$ tyrosine kinase receptor that is overexpressed in $40 \%$ to $80 \%$ of NSCLC. ${ }^{98}$ It can be targeted with small-molecule TKIs, such as erlotinib and gefitinib, which bind to the ATP-binding pocket of the receptor. The sequencing of tumor samples from responding patients in clinical trials of TKIs led to the discovery of somatic mutations in the EGFR tyrosine kinase domain. ${ }^{44,45}$ The activating and oncogenic mutations reported to date are in exons 18 to 21 , affecting the tyrosine kinase portion of EGFR. The majority of mutations are either small deletions of exon 19 affecting a 3-amino acid sequence or a point mutation L858R on exon 21. Mutations affecting exon 20, such as small insertions in T790M, account for 3\% to 5\% of all EGFR mutations, and although they are activating, they are also associated with resistance to EGFR TKIs. The prevalence of EGFR mutations varies by ethnicity, from $5 \%$ to $20 \%$ in whites, to $20 \%$ to $40 \%$ in the Asian population; the mutations are less common in black patients. ${ }^{99,100}$ Clinical trials from Japan from Maemondo and colleagues ${ }^{101}$ and from the West Japan Oncology Group, ${ }^{102}$ and from the OPTIMAL study in China, ${ }^{103}$ have shown that TKI therapy in EGFR mutant adenocarcinoma results in response rates of $>70 \%$ and longer progression-free survival when compared with conventional chemotherapy in advanced lung adenocarcinoma. Together, these studies strongly support the role of molecular testing in lung adenocarcinoma for identification of EGFR mutant cancers ${ }^{104}$ and suggest that TKI treatment is the preferred first-line therapy for advanced EGFR mutant tumors. The American Cancer Society has issued a provisional clinical opinion that patients with NSCLC who are being considered for first-line therapy with an EGFR TKI should have their tumor tested for EGFR mutations. ${ }^{105}$

Because key lung cancer mutations are mutually exclusive, an alternative to EGFR mutation testing is K-ras mutation testing. K-ras mutations are present in approximately $30 \%$ of lung adenocarcinomas and are confined to three codons, which lowers the cost and complexity of mutation sequencing. K-ras-mutationpositive tumors are resistant to TKI therapy; thus, a positive test obviates the need for EGFR mutation testing. Adenocarcinomas that are negative for EGFR and K-ras mutations can be screened by FISH for the presence of chromosomal translocation of the ALK gene. ALK gene translocations, mainly EML4/ALK, were recently identified as an oncogenic mechanism in NSCLC, present in 3\% to 5\% of tumors, predominantly adenocarcinoma. ${ }^{52}$ Kwak and colleagues ${ }^{106}$ published the first human experience with ALK inhibition through the use of the dual ALK/MET inhibitor crizotinib
(PF-02341066) in patients with ALK-translocated, advanced lung carcinoma. In 82 patients with FISHtesting-confirmed translocations, crizotinib at a dose of $250 \mathrm{mg}$ po bid led to a dramatic $57 \%$ response rate and a 6 -month progression-free survival of $72 \%$. Subsequently, based on data from this phase 1 trial, crizotinib has been approved by the FDA for the treatment of patients with NSCLC tumors that harbor the ALK translocation as detected by an FDA-approved FISH test. In line with recommendations from the American Society of Clinical Oncology, we recommend testing for molecular alterations in EGFR, K-ras, or ALK in advanced-stage lung adenocarcinoma (see the article by Socinski et al ${ }^{27}$ "Treatment of Stage IV Non-small Cell Lung Cancer," in the American College of Chest Physicians Lung Cancer Guidelines). Sequential testing for EGFR, K-ras, and ALK is reasonable, beginning with either K-ras or EGFR analysis, with ALK analysis reserved for K-ras- and EGFR-negative specimens. Concomitant testing is not necessary unless sequential testing causes a delay in treatment.

Despite the high frequency of clinical response seen in patients treated with TKIs for EGFR mutant lung tumors and with crizotinib for tumors that are positive for ALK, drug resistance and relapse invariably develop. ${ }^{97}$ Research directed toward understanding the biology of acquired resistance in these tumors indicates that tumors can evade inhibition through a variety of complex mechanisms. For example, Katayama and colleagues ${ }^{107}$ examined tumor biopsy specimens from 18 patients with crizotinib resistance and determined that resistance was attributable to acquired ALK somatic mutations in five cases and to alternative mechanisms of resistance, including activation of other tyrosine kinase receptors such as EGFR and KIT, in others. Sequist and colleagues ${ }^{108}$ examined tumor biopsy specimens from 37 patients with EGFRmutation-positive tumors with acquired resistance to TKIs. Interestingly, five resistant tumors developed a morphology that was consistent with small cell carcinoma and were sensitive to small cell therapies. Importantly, three patients showed resolution of the resistance alteration in the absence of EGFR inhibitors and were, thus, sensitive to the resumption of therapy. These studies indicate that biopsies of resistant tumors may provide important information that can guide subsequent therapy.

\subsection{Molecular Profiling in EARly-STAGe LUNG CANCER}

To discriminate a poor prognosis from a good prognosis in early-stage lung cancers, a multitude of geneprofiling studies have been conducted on early-stage NSCLC, each proposing a signature of prognostic genomic information that correlates with patient 
outcomes, and may subsequently guide decisions regarding adjuvant chemotherapy. ${ }^{109-110}$ However, the lack of reproducibility of signatures among independent studies raises concerns for implementation of this technology in routine clinical practice. Variations in patient selection, platforms, and statistical interpretation among studies and a lack of evaluation in prospective clinical trials have all been implicated as contributing factors to this issue. ${ }^{111}$

Studies integrating gene signatures into clinical trials are beginning to demonstrate promise. Zhu et al ${ }^{112}$ demonstrated that a 15-gene tumor signature derived from patients enrolled in the JBR.10 adjuvant chemotherapy trial (National Cancer Institute of Canada Clinical Trials Group) could successfully identify high-risk patients who would benefit from adjuvant therapy. ${ }^{112}$

Gene signatures in noninvasive specimens continue to be examined for the purpose of early diagnosis of lung cancer. However, several issues remain in the search for a noninvasive biomarker, including selection of proper source (eg, blood vs sputum), selection of the ideal profiling method, and analysis of data. Thus, gene expression profiling of sputum, airway, and blood shows promise but will require a extensive validation and prospective evaluation prior to clinical application. ${ }^{113-116}$

\subsection{CONCLUSION}

Despite the small improvements in lung cancer 5 -year survival over the past 3 decades, there is cause to be optimistic for a future with fewer lung cancer deaths. This future will deploy molecular techniques to diagnose lung cancer earlier and will continue to translate laboratory-based investigations of lung cancer into diagnostics and novel therapeutics that will have a significant impact on improving lung cancer survival. Recent technologic developments ${ }^{117}$ promise a preponderance of high-throughput data and novel disease insights that will continue to propel diagnostics and therapeutics toward a future with reduced lung cancer morbidity and mortality.

\section{ACKNOWLEDGMENTS}

Author contributions: Dr Powell had full access to all of the data in the study and takes responsibility for the integrity of the data and the accuracy of the data analysis.

Dr Nana-Sinkam: contributed to the literature search and drafting and revision of the manuscript.

Dr Powell: contributed to the literature search and drafting and revision of the manuscript.

Financial/nonfinancial disclosures: The authors have reported to CHEST that no potential conflicts of interest exist with any companies/organizations whose products or services may be discussed in this article.

Role of Sponsors: The American College of Chest Physicians was solely responsible for the development of these guidelines. The remaining supporters played no role in the development process. External supporting organizations cannot recommend panelists or topics, nor are they allowed prepublication access to the manuscripts and recommendations. Further details on the Conflict of Interest Policy are available online at http://chestnet.org. Endorsements: This guideline is endorsed by the European Society of Thoracic Surgeons, Oncology Nursing Society, American Association for Bronchology and Interventional Pulmonology, and the Society of Thoracic Surgeons.

\section{REFERENCES}

1. Lewis SZ, Diekemper R, Addrizzo-Harris DJ. Methodology for development of guidelines for lung cancer: diagnosis and management of lung cancer, 3rd ed: American College of Chest Physicians evidence-based clinical practice guidelines. Chest. 2013;143(5)(suppl):41S-50S

2. Jemal A, Bray F, Center MM, Ferlay J, Ward E, Forman D. Global cancer statistics. CA Cancer J Clin. 2011;61(2):69-90.

3. Hanahan D, Weinberg RA. Hallmarks of cancer: the next generation. Cell. 2011;144(5):646-674.

4. Hanahan D, Weinberg RA. The hallmarks of cancer. Cell. 2000;100(1):57-70.

5. Wistuba II, Lam S, Behrens C, et al. Molecular damage in the bronchial epithelium of current and former smokers. J Natl Cancer Inst. 1997;89(18):1366-1373.

6. Powell CA, Klares S, O’Connor G, Brody JS. Loss of heterozygosity in epithelial cells obtained by bronchial brushing: clinical utility in lung cancer. Clin Cancer Res. 1999;5(8): 2025-2034.

7. Carpagnano GE, Foschino-Barbaro MP, Spanevello A, et al. $3 p$ microsatellite signature in exhaled breath condensate and tumor tissue of patients with lung cancer. Am J Respir Crit Care Med. 2008;177(3):337-341.

8. Chiba I, Takahashi T, Nau MM, et al; Lung Cancer Study Group. Mutations in the p53 gene are frequent in primary, resected non-small cell lung cancer. Oncogene. 1990;5(10): $1603-1610$

9. Rusin MR, Okamoto A, Chorazy M, et al. Intragenic mutations of the p16(INK4), p15(INK4B) and p18 genes in primary nonsmall-cell lung cancers. Int J Cancer. 1996;65(6):734-739.

10. Ding L, Getz G, Wheeler DA, et al. Somatic mutations affect key pathways in lung adenocarcinoma. Nature. 2008; 455(7216):1069-1075.

11. Lee W, Jiang Z, Liu J, et al. The mutation spectrum revealed by paired genome sequences from a lung cancer patient. Nature. 2010;465(7297):473-477.

12. Su Z, Dias-Santagata D, Duke M, et al. A platform for rapid detection of multiple oncogenic mutations with relevance to targeted therapy in non-small-cell lung cancer. J Mol Diagn. 2011;13(1):74-84.

13. Borràs E, Jurado I, Hernan I, et al. Clinical pharmacogenomic testing of KRAS, BRAF and EGFR mutations by high resolution melting analysis and ultra-deep pyrosequencing. BMC Cancer. 2011;11:406.

14. Querings S, Altmüller J, Ansén S, et al. Benchmarking of mutation diagnostics in clinical lung cancer specimens. PLoS ONE. 2011;6(5):e19601.

15. Reya T, Morrison SJ, Clarke MF, Weissman IL. Stem cells, cancer, and cancer stem cells. Nature. 2001;414(6859):105-111.

16. Heguy A, O'Connor TP, Luettich K, et al. Gene expression profiling of human alveolar macrophages of phenotypically normal smokers and nonsmokers reveals a previously unrecognized subset of genes modulated by cigarette smoking. J Mol Med (Berl). 2006;84(4):318-328.

17. Borczuk AC, Powell CA. Expression profiling and lung cancer development. Proc Am Thorac Soc. 2007;4(1):127-132.

18. Borczuk AC, Gorenstein L, Walter KL, Assaad AA, Wang L, Powell CA. Non-small-cell lung cancer molecular signatures recapitulate lung developmental pathways. Am J Pathol. 2003;163(5):1949-1960. 
19. Bonner AE, Lemon WJ, Devereux TR, Lubet RA, You M. Molecular profiling of mouse lung tumors: association with tumor progression, lung development, and human lung adenocarcinomas. Oncogene. 2004;23(5):1166-1176.

20. Liu H, Kho AT, Kohane IS, Sun Y. Predicting survival within the lung cancer histopathological hierarchy using a multi-scale genomic model of development. PLoS Med. 2006;3(7):e232.

21. Glinsky GV, Berezovska O, Glinskii AB. Microarray analysis identifies a death-from-cancer signature predicting therapy failure in patients with multiple types of cancer. J Clin Invest. 2005;115(6):1503-1521.

22. Johnson DH, Fehrenbacher L, Novotny WF, et al. Randomized phase II trial comparing bevacizumab plus carboplatin and paclitaxel with carboplatin and paclitaxel alone in previously untreated locally advanced or metastatic non-smallcell lung cancer. J Clin Oncol. 2004;22(11):2184-2191.

23. Sandler A, Gray R, Perry MC, et al. Paclitaxel-carboplatin alone or with bevacizumab for non-small-cell lung cancer. N Engl J Med. 2006;355(24):2542-2550.

24. Scagliotti G, Brodowicz T, Shepherd FA, et al. Treatmentby-histology interaction analyses in three phase III trials show superiority of pemetrexed in nonsquamous non-small cell lung cancer. J Thorac Oncol. 2011;6(1):64-70.

25. Langer CJ, Besse B, Gualberto A, Brambilla E, Soria JC. The evolving role of histology in the management of advanced non-small-cell lung cancer. J Clin Oncol. 2010; 28(36):5311-5320.

26. Travis WD, Brambilla E, Noguchi M, et al. International Association for the Study of Lung Cancer/American Thoracic Society/European Respiratory Society international multidisciplinary classification of lung adenocarcinoma. J Thorac Oncol. 2011;6(2):244-285.

27. Socinski MA, Evans T, Gettinger S. Treatment of stage IV non-small cell lung cancer: diagnosis and management of lung cancer, 3rd ed: American College of Chest Physicians evidence-based clinical practice guidelines. Chest. 2013; 143(5)(suppl):e341S-e368S.

28. Bulman W, Saqi A, Powell CA. Acquisition and processing of endobronchial ultrasound-guided transbronchial needle aspiration specimens in the era of targeted lung cancer chemotherapy. Am J Respir Crit Care Med. 2012;185(6): 606-611.

29. Loo PS, Thomas SC, Nicolson MC, Fyfe MN, Kerr KM. Subtyping of undifferentiated non-small cell carcinomas in bronchial biopsy specimens. J Thorac Oncol. 2010;5(4): 442-447.

30. Nicholson AG, Gonzalez D, Shah P, et al. Refining the diagnosis and EGFR status of non-small cell lung carcinoma in biopsy and cytologic material, using a panel of mucin staining, TTF-1, cytokeratin 5/6, and P63, and EGFR mutation analysis. J Thorac Oncol. 2010;5(4):436-441.

31. Schwartz AM, Rezaei MK. Diagnostic surgical pathology in lung cancer: diagnosis and management of lung cancer, 3rd ed: American College of Chest Physicians evidencebased clinical practice guidelines. Chest. 2013;143(5)(suppl): e251S-e262S.

32. Rock JR, Onaitis MW, Rawlins EL, et al. Basal cells as stem cells of the mouse trachea and human airway epithelium. Proc Natl Acad Sci U S A. 2009;106(31):12771-12775.

33. Bertolini G, Roz L, Perego P, et al. Highly tumorigenic lung cancer CD133+ cells display stem-like features and are spared by cisplatin treatment. Proc Natl Acad Sci U S A. 2009;106(38):16281-16286.

34. Jiang F, Qiu Q, Khanna A, et al. Aldehyde dehydrogenase 1 is a tumor stem cell-associated marker in lung cancer. $\mathrm{Mol}$ Cancer Res. 2009;7(3):330-338.
35. Kim CF, Jackson EL, Woolfenden AE, et al. Identification of bronchioalveolar stem cells in normal lung and lung cancer. Cell. 2005;121(6):823-835.

36. Schenk T, Ackermann J, Brunner C, et al. Detection of chromosomal aneuploidy by interphase fluorescence in situ hybridization in bronchoscopically gained cells from lung cancer patients. Chest. 1997;111(6):1691-1696.

37. Sokolova IA, Bubendorf L, O’Hare A, et al. A fluorescence in situ hybridization-based assay for improved detection of lung cancer cells in bronchial washing specimens. Cancer. 2002;96(5):306-315.

38. Nakamura H, Aute I, Kawasaki N, Taguchi M, Ohira T, Kato H. Quantitative detection of lung cancer cells by fluorescence in situ hybridization: comparison with conventional cytology. Chest. 2005;128(2):906-911.

39. Halling KC, Rickman OB, Kipp BR, Harwood AR, Doerr CH, Jett JR. A comparison of cytology and fluorescence in situ hybridization for the detection of lung cancer in bronchoscopic specimens. Chest. 2006;130(3):694-701.

40. Yendamuri S, Vaporciyan AA, Zaidi T, et al. 3p22.1 and 10q22.3 deletions detected by fluorescence in situ hybridization (FISH): a potential new tool for early detection of non-small cell lung Cancer (NSCLC). J Thorac Oncol. 2008; 3(9):979-984.

41. Varella-Garcia M, Kittelson J, Schulte AP, et al. Multi-target interphase fluorescence in situ hybridization assay increases sensitivity of sputum cytology as a predictor of lung cancer. Cancer Detect Prev. 2004;28(4):244-251.

42. Bubendorf L, Müller P, Joos L, et al. Multitarget FISH analysis in the diagnosis of lung cancer. Am J Clin Pathol. 2005;123(4):516-523.

43. Varella-Garcia M, Schulte AP, Wolf HJ, et al. The detection of chromosomal aneusomy by fluorescence in situ hybridization in sputum predicts lung cancer incidence. Cancer Prev Res (Phila). 2010;3(4):447-453.

44. Lynch TJ, Bell DW, Sordella R, et al. Activating mutations in the epidermal growth factor receptor underlying responsiveness of non-small-cell lung cancer to gefitinib. $N$ Engl J Med. 2004;350(21):2129-2139.

45. Paez JG, Jänne PA, Lee JC, et al. EGFR mutations in lung cancer: correlation with clinical response to gefitinib therapy. Science. 2004;304(5676):1497-1500.

46. Chang JW, Liu HP, Hsieh MH, et al. Increased epidermal growth factor receptor (EGFR) gene copy number is strongly associated with EGFR mutations and adenocarcinoma in non-small cell lung cancers: a chromogenic in situ hybridization study of 182 patients. Lung Cancer. 2008;61(3):328-339.

47. Pinter F, Papay J, Almasi A, et al. Epidermal growth factor receptor (EGFR) high gene copy number and activating mutations in lung adenocarcinomas are not consistently accompanied by positivity for EGFR protein by standard immunohistochemistry. J Mol Diagn. 2008;10(2):160-168.

48. Goss G, Ferry D, Wierzbicki R, et al. Randomized phase II study of gefitinib compared with placebo in chemotherapynaive patients with advanced non-small-cell lung cancer and poor performance status. J Clin Oncol. 2009;27(13):2253-2260.

49. Hirsch FR, Varella-Garcia M, Bunn PA Jr, et al. Molecular predictors of outcome with gefitinib in a phase III placebocontrolled study in advanced non-small-cell lung cancer. J Clin Oncol. 2006;24(31):5034-5042.

50. Dahabreh IJ, Linardou H, Kosmidis P, Bafaloukos D, Murray S. EGFR gene copy number as a predictive biomarker for patients receiving tyrosine kinase inhibitor treatment: a systematic review and meta-analysis in non-small-cell lung cancer. Ann Oncol. 2011;22(3):545-552.

51. Dahabreh IJ, Linardou H, Siannis F, Kosmidis P, Bafaloukos D, Murray S. Somatic EGFR mutation and gene copy gain 
as predictive biomarkers for response to tyrosine kinase inhibitors in non-small cell lung cancer. Clin Cancer Res. 2010;16(1):291-303.

52. Soda M, Choi YL, Enomoto M, et al. Identification of the transforming EML4-ALK fusion gene in non-small-cell lung cancer. Nature. 2007;448(7153):561-566.

53. Solomon B, Varella-Garcia M, Camidge DR. ALK gene rearrangements: a new therapeutic target in a molecularly defined subset of non-small cell lung cancer.J Thorac Oncol. 2009;4(12):1450-1454.

54. Just PA, Cazes A, Audebourg A, et al. Histologic subtypes, immunohistochemistry, FISH or molecular screening for the accurate diagnosis of ALK-rearrangement in lung cancer a comprehensive study of Caucasian non-smokers. Lung Cancer. 2012;76(3):309-315.

55. Maier S, Wilbertz T, Braun M, et al. SOX2 amplification is a common event in squamous cell carcinomas of different organ sites. Hum Pathol. 2011;42(8):1078-1088.

56. Bass AJ, Watanabe H, Mermel CH, et al. SOX2 is an amplified lineage-survival oncogene in lung and esophageal squamous cell carcinomas. Nat Genet. 2009;41(11):1238-1242.

57. Tsuta K, Tanabe Y, Yoshida A, et al. Utility of 10 immunohistochemical markers including novel markers (desmocollin-3, glypican 3, S100A2, S100A7, and Sox-2) for differential diagnosis of squamous cell carcinoma from adenocarcinoma of the lung. J Thorac Oncol. 2011;6(7):1190-1199.

58. Wilbertz T, Wagner P, Petersen K, et al. SOX2 gene amplification and protein overexpression are associated with better outcome in squamous cell lung cancer. Mod Pathol. 2011; 24(7):944-953.

59. Sholl LM, Barletta JA, Yeap BY, Chirieac LR, Hornick JL. Sox2 protein expression is an independent poor prognostic indicator in stage I lung adenocarcinoma. Am J Surg Pathol. 2010;34(8):1193-1198.

60. Weiss J, Sos ML, Seidel D, et al. Frequent and focal FGFR1 amplification associates with therapeutically tractable FGFR1 dependency in squamous cell lung cancer. Sci Transl Med. 2010;2(62):62ra93.

61. Goeke F, Franzen A, Menon R, et al. Rationale for treatment of metastatic squamous cell carcinoma of the lung using FGFR Inhibitors [published online ahead of print April 12, 2012]. Chest. In press.

62. Gozgit JM, Wong MJ, Moran L, et al. Ponatinib (AP24534), a multitargeted pan-FGFR inhibitor with activity in multiple FGFR-amplified or mutated cancer models. Mol Cancer Ther. 2012;11(3):690-699.

63. Tessema M, Belinsky SA. Mining the epigenome for methylated genes in lung cancer. Proc Am Thorac Soc. 2008;5(8): 806-810.

64. Toyooka S, Tokumo M, Shigematsu H, et al. Mutational and epigenetic evidence for independent pathways for lung adenocarcinomas arising in smokers and never smokers. Cancer Res. 2006;66(3):1371-1375.

65. Kim JS, Kim JW, Han J, Shim YM, Park J, Kim DH. Cohypermethylation of p16 and FHIT promoters as a prognostic factor of recurrence in surgically resected stage I non-small cell lung cancer. Cancer Res. 2006;66(8):4049-4054.

66. Toyooka S, Toyooka KO, Maruyama R, et al. DNA methylation profiles of lung tumors. Mol Cancer Ther. 2001;1(1):61-67.

67. Sterlacci W, Tzankov A, Veits L, et al. A comprehensive analysis of p16 expression, gene status, and promoter hypermethylation in surgically resected non-small cell lung carcinomas. J Thorac Oncol. 2011;6(10):1649-1657.

68. Walter K, Holcomb T, Januario T, et al. DNA methylation profiling defines clinically relevant biological subsets of non-small cell lung cancer. Clin Cancer Res. 2012;18(8): 2360-2373.
69. Leng S, Stidley CA, Liu Y, et al. Genetic determinants for promoter hypermethylation in the lungs of smokers: a candidate gene-based study. Cancer Res. 2012;72(3):707-715.

70. Ostrow KL, Hoque MO, Loyo M, et al. Molecular analysis of plasma DNA for the early detection of lung cancer by quantitative methylation-specific PCR. Clin Cancer Res. 2010; 16(13):3463-3472.

71. Liu Z, Li W, Lei Z, et al. CpG island methylator phenotype involving chromosome $3 p$ confers an increased risk of non-small cell lung cancer. J Thorac Oncol. 2010;5(6): 790-797.

72. Brock MV, Hooker CM, Ota-Machida E, et al. DNA methylation markers and early recurrence in stage I lung cancer. N Engl J Med. 2008;358(11):1118-1128.

73. Belinsky SA, Liechty KC, Gentry FD, et al. Promoter hypermethylation of multiple genes in sputum precedes lung cancer incidence in a high-risk cohort. Cancer Res. 2006; 66(6):3338-3344.

74. Belinsky SA, Grimes MJ, Casas E, et al. Predicting gene promoter methylation in non-small-cell lung cancer by evaluating sputum and serum. Br J Cancer. 2007;96(8):1278-1283.

75. de Fraipont F, Levallet G, Creveuil C, et al; Intergroupe Francophone de Cancérologie Thoracique. An apoptosis methylation prognostic signature for early lung cancer in the IFCT-0002 trial. Clin Cancer Res. 2012;18(10): 2976-2986.

76. Grimson A, Farh KK, Johnston WK, Garrett-Engele P, Lim LP, Bartel DP. MicroRNA targeting specificity in mammals: determinants beyond seed pairing. Mol Cell. 2007;27(1): 91-105.

77. Lee RC, Feinbaum RL, Ambros V. The C. elegans heterochronic gene lin-4 encodes small RNAs with antisense complementarity to lin-14. Cell. 1993;75(5):843-854.

78. Friedman RC, Farh KK, Burge CB, Bartel DP. Most mammalian mRNAs are conserved targets of microRNAs. Genome Res. 2009;19(1):92-105.

79. Yanaihara N, Caplen N, Bowman E, et al. Unique microRNA molecular profiles in lung cancer diagnosis and prognosis. Cancer Cell. 2006;9(3):189-198.

80. Landi D, Barale R, Gemignani F, Landi S. Prediction of the biological effect of polymorphisms within microRNA binding sites. Methods Mol Biol. 2011;676:197-210.

81. Saito M, Schetter AJ, Mollerup S, et al. The association of microRNA expression with prognosis and progression in earlystage, non-small cell lung adenocarcinoma: a retrospective analysis of three cohorts. Clin Cancer Res. 2011;17(7): 1875-1882.

82. Boeri M, Verri C, Conte D, et al. MicroRNA signatures in tissues and plasma predict development and prognosis of computed tomography detected lung cancer. Proc Natl Acad Sci U S A. 2011;108(9):3713-3718.

83. Voortman J, Goto A, Mendiboure J, et al. MicroRNA expression and clinical outcomes in patients treated with adjuvant chemotherapy after complete resection of non-small cell lung carcinoma. Cancer Res. 2010;70(21):8288-8298.

84. Del Vescovo V, Cantaloni C, Cucino A, et al. miR-205 Expression levels in nonsmall cell lung cancer do not always distinguish adenocarcinomas from squamous cell carcinomas. Am J Surg Pathol. 2011;35(2):268-275.

85. Bishop JA, Benjamin H, Cholakh H, Chajut A, Clark DP, Westra WH. Accurate classification of non-small cell lung carcinoma using a novel microRNA-based approach. Clin Cancer Res. 2010;16(2):610-619.

86. Lebanony D, Benjamin H, Gilad S, et al. Diagnostic assay based on hsa-miR-205 expression distinguishes squamous from nonsquamous non-small-cell lung carcinoma. J Clin Oncol. 2009;27(12):2030-2037. 
87. Mueller MM, Fusenig NE. Friends or foes - bipolar effects of the tumour stroma in cancer. Nat Rev Cancer. 2004;4(11): 839-849.

88. Tisty TD, Coussens LM. Tumor stroma and regulation of cancer development. Annu Rev Pathol. 2006;1:119-150.

89. Joyce JA, Pollard JW. Microenvironmental regulation of metastasis. Nat Rev Cancer. 2009;9(4):239-252.

90. Borczuk AC, Sole M, Lu P, et al. Progression of human bronchioloalveolar carcinoma to invasive adenocarcinoma is modeled in a transgenic mouse model of K-ras-induced lung cancer by loss of the TGF- $\beta$ type II receptor. Cancer Res. 2011;71(21):6665-6675.

91. Olumi AF, Grossfeld GD, Hayward SW, Carroll PR, Tlsty TD, Cunha GR. Carcinoma-associated fibroblasts direct tumor progression of initiated human prostatic epithelium. Cancer Res. 1999;59(19):5002-5011.

92. Bhowmick NA, Chytil A, Plieth D, et al. TGF-beta signaling in fibroblasts modulates the oncogenic potential of adjacent epithelia. Science. 2004;303(5659):848-851.

93. Malanchi I, Santamaria-Martínez A, Susanto E, et al. Interactions between cancer stem cells and their niche govern metastatic colonization. Nature. 2011;481(7379):85-89.

94. Kaplan RN, Riba RD, Zacharoulis S, et al. VEGFR1-positive haematopoietic bone marrow progenitors initiate the premetastatic niche. Nature. 2005;438(7069):820-827.

95. Bremnes RM, Al-Shibli K, Donnem T, et al. The role of tumor-infiltrating immune cells and chronic inflammation at the tumor site on cancer development, progression, and prognosis: emphasis on non-small cell lung cancer. J Thorac Oncol. 2011;6(4):824-833.

96. Weinstein IB. Cancer. Addiction to oncogenes-the Achilles heal of cancer. Science. 2002;297(5578):63-64.

97. Cheng H, Xu X, Costa DB, Powell CA, Halmos B. Molecular testing in lung cancer: the time is now. Curr Oncol Rep. 2010;12(5):335-348.

98. Hirsch FR, Varella-Garcia M, Cappuzzo F. Predictive value of EGFR and HER2 overexpression in advanced non-smallcell lung cancer. Oncogene. 2009;28(suppl 1):S32-S37.

99. Tokumo M, Toyooka S, Kiura K, et al. The relationship between epidermal growth factor receptor mutations and clinicopathologic features in non-small cell lung cancers. Clin Cancer Res. 2005;11(3):1167-1173

100. John T, Liu G, Tsao MS. Overview of molecular testing in non-small-cell lung cancer: mutational analysis, gene copy number, protein expression and other biomarkers of EGFR for the prediction of response to tyrosine kinase inhibitors. Oncogene. 2009;28(suppl 1):S14-S23.

101. Maemondo M, Inoue A, Kobayashi K, et al; North-East Japan Study Group. Gefitinib or chemotherapy for nonsmall-cell lung cancer with mutated EGFR. $N$ Engl J Med. 2010;362(25):2380-2388.

102. Mitsudomi T, Morita S, Yatabe Y, et al; West Japan Oncology Group. Gefitinib versus cisplatin plus docetaxel in patients with non-small-cell lung cancer harbouring mutations of the epidermal growth factor receptor (WJTOG3405): an open label, randomised phase 3 trial. Lancet Oncol. 2010;11(2): 121-128.
103. Zhou C, Wu YL, Chen G, et al. Erlotinib versus chemotherapy as first-line treatment for patients with advanced EGFR mutation-positive non-small-cell lung cancer (OPTIMAL, CTONG-0802): a multicentre, open-label, randomised, phase 3 study. Lancet Oncol. 2011;12(8):735-742.

104. Zhang Z, Stiegler AL, Boggon TJ, Kobayashi S, Halmos B. EGFR-mutated lung cancer: a paradigm of molecular oncology. Oncotarget. 2010;1(7):497-514.

105. Keedy VL, Temin S, Somerfield MR, et al. American Society of Clinical Oncology provisional clinical opinion: epidermal growth factor receptor (EGFR) mutation testing for patients with advanced non-small-cell lung cancer considering firstline egfr tyrosine kinase inhibitor therapy. J Clin Oncol. 2011; 29(15):2121-2127.

106. Kwak EL, Bang YJ, Camidge DR, et al. Anaplastic lymphoma kinase inhibition in non-small-cell lung cancer. $N$ Engl J Med. 2010;363(18):1693-1703.

107. Katayama R, Shaw AT, Khan TM, et al. Mechanisms of acquired crizotinib resistance in ALK-rearranged lung cancers. Sci Transl Med. 2012;4(120):120ra17.

108. Sequist LV, Waltman BA, Dias-Sangagata D, et al. Genotypic and histological evolution of lung cancers acquiring resistance to EGFR inhibitors. Sci Transl Med. 2011;3(75): $75 \mathrm{ra} 26$.

109. Beer DG, Kardia SL, Huang CC, et al. Gene-expression profiles predict survival of patients with lung adenocarcinoma. Nat Med. 2002;8(8):816-824.

110. Shedden K, Taylor JM, Enkemann SA, et al; Director's Challenge Consortium for the Molecular Classification of Lung Adenocarcinoma. Gene expression-based survival prediction in lung adenocarcinoma: a multi-site, blinded validation study. Nat Med. 2008;14(8):822-827.

111. Subramanian J, Simon R. Gene expression-based prognostic signatures in lung cancer: ready for clinical use? J Natl Cancer Inst. 2010;102(7):464-474.

112. Zhu CQ, Ding K, Strumpf D, et al. Prognostic and predictive gene signature for adjuvant Chemotherapy in resected non-small cell lung cancer. J Clin Oncol. 2010;28(29): 4417-4424.

113. Spira A, Beane JE, Shah V, et al. Airway epithelial gene expression in the diagnostic evaluation of smokers with suspect lung cancer. Nat Med. 2007;13(3):361-366.

114. Zander T, Hofmann A, Staratschek-Jox A, et al. Blood-based gene expression signatures in non-small cell lung cancer. Clin Cancer Res. 2011;17(10):3360-3367.

115. Rotunno M, Hu N, Su H, et al. A gene expression signature from peripheral whole blood for stage I lung adenocarcinoma. Cancer Prev Res (Phila). 2011;4(10):1599-1608.

116. Showe MK, Vachani A, Kossenkov AV, et al. Gene expression profiles in peripheral blood mononuclear cells can distinguish patients with non-small cell lung cancer from patients with nonmalignant lung disease. Cancer Res. 2009; 69(24):9202-9210

117. Ocak S, Sos ML, Thomas RK, Massion PP. High-throughput molecular analysis in lung cancer: insights into biology and potential clinical applications. Eur Respir J. 2009;34(2): 489-506. 